\title{
ELECTRICAL TREEING PROPAGATION IN NANOCOMPOSITES AND THE ROLE OF NANOFILLERS: SIMULATION WITH THE AID OF CELLULAR AUTOMATA
}

\author{
Despoina Pitsa * - George Vardakis * - \\ Michael G. Danikas* - Masahiro Kozako ${ }^{* *}$
}

\begin{abstract}
In this paper the propagation of electrical treeing in nanodielectrics using the DIMET (Dielectric Inhomogeneity Model for Electrical Treeing) is studied. The DIMET is a model which simulates the growth of electrical treeing based on theory of Cellular Automata. Epoxy/glass nanocomposites are used as samples between a needle-plane electrode arrangement. The diameter of nanofillers is $100 \mathrm{~nm}$. The electric treeing, which starts from the needle electrode, is examined. The treeing growth seems to be stopped by the nanofillers. The latter act as elementary barriers to the treeing propagation.
\end{abstract}

K e y w or ds: electrical trees, nanocomposites, nanofillers, breakdown, tree growth

\section{INTRODUCTION}

Polymer nanocomposites are polymers which include a small amount of nanofillers. Epoxy resin is an insulating material with superior properties, which is used in several electrical applications. Composites of epoxy resins with nanofillers can be used as insulating materials with superior electrical, mechanical and thermal properties. Epoxy-layered silicates showed a higher insulation breakdown strength than the base resin, this is due to the delay of appearance of electric treeing [1]. Epoxy nanocomposites appear higher partial discharge $(\mathrm{PD})$ resistance than base epoxy resins [2,3]. Epoxy nanocomposite systems with inorganic showed superior dielectric properties at low nanofiller contents than base epoxy systems [4]. The unique electrical and electromechanical properties of interfaces between the nanoparticles and the surrounding matrix influence the properties of nanocomposites [5]. The interaction zone plays a major role to the different electric properties of nanocomposites. When the size of nanofillers decreases, and its dimesions approach the dimesions of the polymer chain length, the interfacial region increases. This interfacial region creates an interaction zone which does not lead to a Maxwell-Wagner polarization, as expected in a conventional composite, but to an interfacial polarization [6-8].

Electrical treeing is a well known aging mechanism of solid dielectrics. Tree propagation includes the formation of new branches. These new branches are formed by the degradation of the material due to the PD activity in the primary branches [9]. The resistance to treeing breakdown is higher in epoxy/ZnO nanocomposites than in base epoxy resin. The addition of a small amount of
$\mathrm{ZnO}$ nanofillers in the epoxy resin may lead to a greater resistance to tree growth in the nanocomposite [10]. In the present paper, the influence of nanoparticles on the propagation of electrical treeing is examined with the aid of Cellular Automata (CA).

\section{CELLULAR AUTOMATA AND THE ELECTRODE ARRANGEMENT}

Cellular Automata (CA) are models which are used in order to simulate real systems. CA consists of four components [11]:

- a grid of cells,

- a group of variables,

- a group of local rules which specify the behavior of the variables,

- initial condition.

The grid which is used in this study is two dimensional. The grid consists of $5000 \times 5000$ cells. Every cell is surrounded by eight neighbor cells. This neighborhood is called Moore neighborhood, Fig. 1. The distinctive state of the cell $A$ is determined by the distinctive state of the eight neighbor $B$ cells at every time step.

The point-plane arrangement was created at the Partial Differential Equation (PDE) Toolbox of MATLAB. The point electrode is the high DC voltage electrode, whereas the plane electrode is grounded. The point electrode is introduced into the specimen. The specimen is a nanocomposite. The nanofillers are dispersed near the point electrode. A nanocomposite has been created under the point electrode. A nanofiller is represented by a cell. The dimension of each cell is $100 \times 100 \mathrm{~nm}$. A cell could

\footnotetext{
* Democritus University of Thrace, Department of Electrical and Computer Engineering, Power Systems Laboratory, 67100 Xanthi, Greece $^{* *}$ Kyushu Institute of Technology, Department of Electrical Engineering and Electronics, 1-1 Sensui-cho, Tobata-ku, Kitakyushushi, Fukuoka 804-8550, Japan
} 


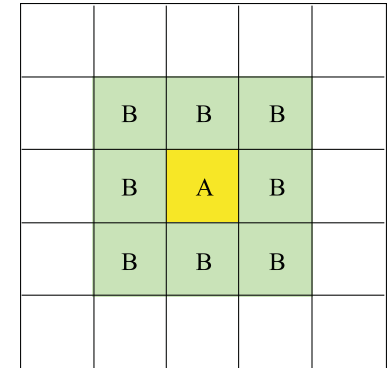

Fig. 1. The Moore neighborhood [11]

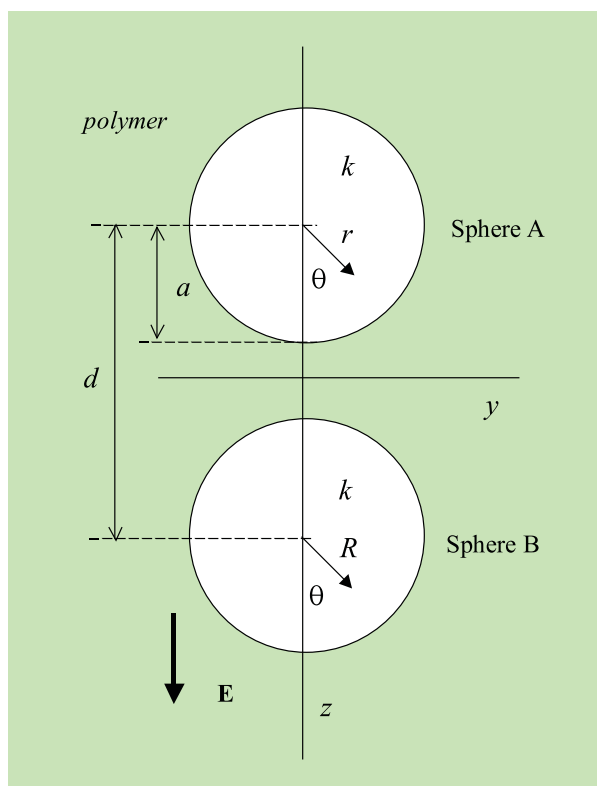

Fig. 2. Two identical spheres subjected to an external electric field [13]

belong to the electrodes or to the polymer or to the tree or could be a nanofiller. The distance between the two electrodes is $0.4 \mathrm{~mm}$.

\section{THE SIMULATION PROCESS}

The steps during the simulation are the following [12]:

- Creation of the point-plane electrode and the nanocomposite specimen at the PDE Toolbox of MATLAB.

- Application of boundary condition between specimen and air, between polymer matrix and electrodes, between nanofillers and polymer matrix.

- Construction of a $5000 \times 5000$ table with random values between $0.9-1.1$ of the dielectric inhomogeneity factor.

- The Laplace equation (1) is used in case of the absence of space charge, in order to define the distribution of the potential at the arrangement, whereas in the presence of space charge Poissons equation (2) is used.

$$
\begin{aligned}
& \nabla^{2} V=0, \\
& \nabla^{2} V=-\frac{\rho}{\varepsilon} .
\end{aligned}
$$

- Construction of a $5000 \times 5000$ table with the values of the potential of each cell.

- Calculation of the local electric field:

$$
E=g \frac{V}{d}
$$

( $g$ - is the dielectric inhomogeneity factor, $V-$ is the potential difference between two neighbor cells, $d$ - is the distance between the centers of two neighbor cells).

- If the local electric field $E$ of a cell is greater than the critical value of the electric field $E_{c}$, the cell belongs to the tree. The neighbor cells (Moore neighborhood) around the tip of the point and around the tree are examined.

This process is repeated because during the propagation of the tree, the construction changes, $i e$ the tree structure changes. The whole process is described in [12] and the treeing propagation based on the method of CA was given the name of DIMET (Dielectric Inhomogeneity Model for Electrical Treeing).

Between the specimen and the air the Neumann boundary conditions are applied

$$
\mathbf{n} \varepsilon \cdot \nabla V+q V=g
$$

( $\boldsymbol{n}$ - is the vertical vector, $\varepsilon-$ is the relative permittivity of the polymer, $q$ - is the charge, $V$-is the electric potential, $g$ - is the surface charge), $q=0, g=0$.

Between the polymer and the nanofillers and the polymer and the electrodes the Dirichlet boundary conditions are applied

$$
h V=r
$$

( $V$ - is the electric potential, $h=1-$ is the weight).

The potential at the surface of two identical dielectric spheres A and B subjected to an external electric field, Fig. 2, is given by [13]

$$
\Phi_{i}=\frac{E d}{2}-\sum_{n=1}^{\infty} a_{n}\left[\left(\frac{a}{d}\right)^{n+1}+\frac{2 n+1}{n(k-1)}(-1)^{n} P_{n}(\lambda)\right]
$$$$
\text { for } A \text { sphere, }
$$

$$
\begin{array}{r}
\Phi_{i}=-\frac{E d}{2}+\sum_{n=1}^{\infty} a_{n}\left[\left(\frac{a}{d}\right)^{n+1}+\frac{2 n+1}{n(k-1)}(-1)^{n} P_{n}(\Lambda)\right] \\
\text { for } B \text { sphere. }
\end{array}
$$

$E$ - is the external electric field, $d$ - is the distance between the centers of the two spheres, $\alpha$ - is the radius, $k$ - is the ratio of the relative permittivity of the polymer/relative permittivity of the nanofillers, $\lambda=\cos \theta$, $\Lambda=\cos \Theta, P_{n}-$ is the Legendre polynomial of order $n$, $A=(I-U)^{-1} V, A$ and $V$ - are the column vectors, $A=\left[\alpha_{1}, \alpha_{2}, \ldots, \alpha_{N}\right], V=[E \alpha(k-1) /(k+2), 0, \ldots, 0]$, 


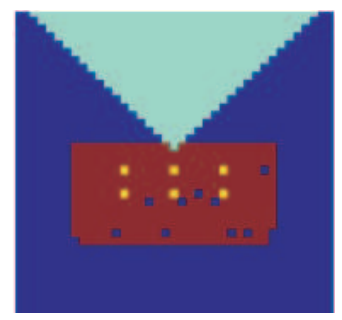

(a)

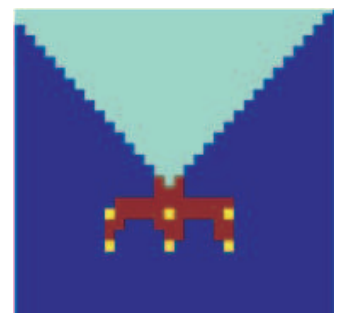

(b)

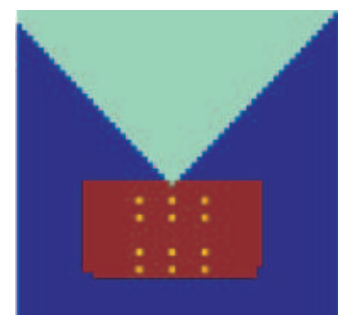

(c)

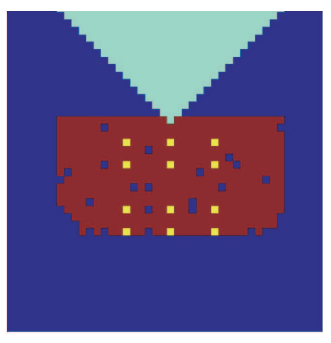

(d)

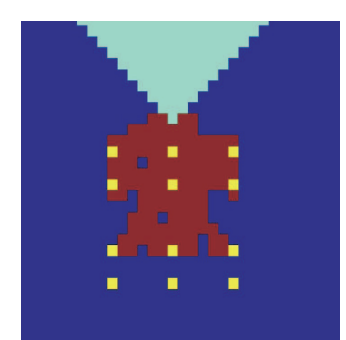

(e)

Fig. 3. Propagation of electrical treeing in a nanocomposite with $20 \mathrm{kV}$ potential at the point electrode and the critical electric intensity (dielectric strength) of $22 \mathrm{kV} / \mathrm{mm}$ : (a) in absence of space charge, (b) in presence of space charge $20 \mathrm{Cb} / \mathrm{m}^{3}$, (c) in absence of space charge, (d) in presence of space charge $-20 \mathrm{Cb} / \mathrm{m}^{3}$, (e) in presence of space charge $20 \mathrm{Cb} / \mathrm{m}^{3}$

$I$ - is the the identity matrix, $U$ - is a square matrix, $U_{n, m}=\frac{n(k-1)}{n(k+1)+1}\left(\frac{a}{d}\right)^{m+n+1} \frac{(m+n) !}{m ! n !}$.

When two spheres are close to each other, they interact [13]. An interaction has also been detected, when two cavities are in close proximity [14]. Thus, interaction between nanofillers can be expected. For the simulations, the equations (6) and (7) have been applied, since these equations can be applied to nanofillers, which are very close to each other [13].

\section{SIMULATION RESULTS AND DISCUSSION}

A nanocomposite is created around the tip of high voltage electrode. Six nanofilers are placed under the point electrode. The potential which is applied at the point electrode is $20 \mathrm{kV}$. The relative permittivity of the polymer matrix and the nanofillers is 4 and 8, respectively. The dielectric strength of the polymer is $22 \mathrm{kV} / \mathrm{mm}$. In case of the presence of space charge, the space charge has been distributed uniformly in the specimen. This is a reasonable assumption since otherwise, the solution of Poisson equation would be difficult. In Fig. 3a, the growth of the electrical tree is shown. The tree growth starts of the tip of the point electrode in the absence of space charge. The electrical treeing propagates around the naonofillers and its growth continues. In Fig. $3 \mathrm{~b}$ the growth of electrical treeing in presence of space charge is shown. The space charge density is $20 \mathrm{Cb} / \mathrm{m}^{3}$. The propagation of the tree has been stopped by the nanofillers. The tree cannot propagate below the last nanofillers.

Six more nanofillers are introduced in the matrix. The results of the simulation in the case of absence of space charge are shown in Fig. 3c. If there are heterocharges (space charge with opposite polarity of the electrode) in the specimen with space charge density $-20 \mathrm{Cb} / \mathrm{m}^{3}$, the results are shown in Fig. 3d. In Fig. 3e the tree propagation in presence of homocharges (space charge with same polarity of the electrode) is shown, with a space charge density of $20 \mathrm{Cb} / \mathrm{m}^{3}$. In Fig. $3 \mathrm{c}$ and $\mathrm{d}$, the propagation of the tree continues through the polymer matrix, whereas in Fig. 3e the propagation of the tree has stopped. In Fig. 3e, the nanofillers act like barriers and seem to prevent the propagation of the trees. The tree grows around the nanofillers, through the polymer, because the nanofillers have a greater resistance to the PD than the polymer [15]. In Fig. 3b and e the nanofillers have stopped the propagation of the electrical tree, which cannot reach the plane electrode and therefore they cannot cause the breakdown of the specimen. The nanofillers, with the help of homocharges, act as an obstacle and delay or even stop the tree growth.

The simulation results of the present study are in agreement with recently published experimental information, where it is shown that nanofillers prevent tree propagation [16]. Trees are prevented from growing straight as the nanofillers offer more PD resistance compared to the surrounding polymer. Nanofillers act as elementary barriers, rendering thus the breakdown strength of the nanocomposite higher than that of the respective conventional polymer. It is true that the present simulation simulates the tree growth with a nanocomposite material with only a few nanofillers. This was unavoidable since to consider many more nanofillers for the simulation, would increase dramatically the computing time. The authors, based on the results of the present study, think that no matter the number of the nanofillers included in the simulation, the result would be the same, namely that nanofillers are elementary barriers to the propagation of electrical trees [17]. 


\section{CONCLUSIONS}

This study shows that nanofillers play a major role in the dielectric properties of nanocomposites and particularly in the propagation of electrical tree. The simulations show that both the homocharge and the nanofillers prevent the growth and propagation of electrical treeing, which stems from a point electrode. The electrical treeing is enclosed between the nanoparticles and cannot propagate neither to the horizontal direction nor to the vertical direction. The most important result is that the nanofillers act as barriers to the propagation of electrical tree. The electrical tree is forced to propagate through the interface between the polymer and the nanofiller because the nanofillers are more resistant to the partial discharges than the polymer. As a result, the tree propagation is delayed and the tree cannot reach the opposite electrode and cause a breakdown. Furthermore, the electrical tree cannot only be delayed by the nanofillers but it can even be stopped. The electrical tree, during its propagation, interacts with many nanofillers and loses part of its energy. As a consequence the electrical tree can not propagate anymore. The delay and/or the total hindrance of tree growth, due to the nanofillers and to the homocharges, can increase the electrical insulation lifetime.

\section{REFERENCES}

[1] IMAI, T.-SAWA, F.-YOSHIMITSU, T.-OZAKI, T.-SHIMIZU, T.: Preparation and Insulation Properties of EpoxyLayered Silicate Nanocomposite, In: 2004 Annual Report Conference on Electrical Insulation and Dielectric Phenomena (CEIDP), Colorado, USA, 17-20 October, 2004, pp. 402-405.

[2] KOZAKO, M.-YAMANO, S.-KIDO, R.-OHKI, Y.-KOHTOH, M. : Evaluation of Epoxy/Alumina Nanocomposites, Proceedings of 2005 International Symposium on Electrical Insulating Materials, Kitakyushu, Japan, June 5-9, 2005, pp. 231- 234.

[3] TANAKA, T.-OHKI, Y.-OCHI, M.-HARADA, M.-IMAI, T. Enhanced Partial Discharge Resistance of Epoxy/Clay Nanocomposite Prepared by Newly Developed Organic Modification and Solubilization Methods, IEEE Transactions on Dielectrics and Electrical Insulation 15 (2008) .

[4] SINGHA, S.-ThOMAS, M. J. : Dielectric Properties of Epoxy Nanocomposites, IEEE Transactions on Dielectrics and Electrical Insulation 15 (2008), 12-23.

[5] LEWIS, T. J. : Interfaces: Nanometric Dielectrics, J. Phys. D.: Appl. Phys. 38 (2005), 202-212.

[6] NELSON, J. K.-FOTHERGILL, J. C.-DissadO, L. A.PEASGOOD, W.: Towards an Understanding of Nanometric Dielectrics, 2002 Annual Report Conference on Electrical Insulation and Dielectric Phenomena, Cancun, Mexico, 20-24 October, 2002, pp. 295-298.

[7] NELSON, J. K.-HU, Y.: Nanocomposite Dielectrics - Properties and Implications, J. Phys. D.: Appl. Phys. 38 (2005), 213-222.

[8] ROY, M.-NELSON, J. K.-MACCRONE, R. K.-SCHADLER, L. S.-REED, C. W.-KEEFE, R.-ZENGER, W. : Polymer Nanocomposite Dielectrics - The Role of the Interface, IEEE Transactions on Dielectrics and Electrical Insulation 12 (2005), 629-643.

[9] NOSKOV, M. D.-SACK, M.-MALINIVSKI, A. S.SCHWAB, A. J.: Measurement and Simulation of Electrical Tree Growth and Partial Discharge Activity in Epoxy Resin, J. Phys. D.: Appl. Phys. 34 (2001), 389-1398.
[10] DIMG, H.-Z.-VARLOW, B. R.: Effect of Nano-Fillers on Electrical Treeing in Epoxy Resin Subjected to AC Voltage, 2004 Annual Report Conference on Electrical Insulation and Dielectric Phenomena (CEIDP), Colorado, USA, 17-20 October, 2004, pp. 332-335.

11] KIER, L. B.-SEYBOLD, P. G.-CHENG, C.: Cellular Automata Modeling of Chemical Systems, Springer, The Netherlands, 2005.

12] VARDAKIS, G. E.-DANIKAS, M. G. : Simulation of Electrical Tree Propagation Using Cellular Automata: The Case of Conducting Particle Included in a Dielectric in Point-Plane Electrode Arrangement, Journal of Electorstatics 63 No. 2 (2005), 129-142.

13] COX, B. J.-THAMWATTANA, Ng.-HILL, J. M.: Electric Field-Induced Force Between Two Identical Uncharged Spheres, Applied Physics Letters 88 (2006), 152903.

14] DANIKAS, M. G.: Partial Discharge Behaviour of Two (or More) Adjacent Cavities in Polyethylene Samples, J. Electr. Eng. 52 (2001), 36-39.

15] AlaPATI, S.-THOMAS, M. J. Electrical Treeing in Polymer Nanocomposites : 15th National Power Systems Conference (NPSC), pp. 351-355, IIT Bombay, December, 2008.

16] DANIKAS, M. G.-TANAKA, T. : Nanocomposites: A Review on Electrical Treeing and Breakdown, accepted for publication in IEEE Electr. Insul. Mag.

17] IMAI, T.-SAWA, F.-OZAKI, T.-SHIMIZU, T.-KUGE, S.-KOZAKO, M.-TANAKA, T. : Effect of Epoxy/Filler Interface on Nano or Micro-Composites, IEEJ Transactions on Fundamentals and Materials 126 No. 2 (2006), 84-91.

Received 27 May 2009

Despoina Pitsa has finished her first degree in the Department of Electrical and Computer Engineering, Democritus University of Thrace, in 2007 and her MSc in 2009. She is now candidate for a $\mathrm{PhD}$. Her research interests are in small partial discharges in gas and solid insulating materials, and simulation of electrical treeing in polymers and in nanocomposites.

George Vardakis is a physicist who received his first degree from Aristotle University of Thessaloniki. He received his Ph.D. in 2006 from Democritus University of Thrace, Department of Electrical and Computer Engineering. His research interests include small partial discharges in solid dielectrics, simulation of electrical trees in polymeric materials and in nanocomposites. He is also interested in the modeling of partial discharge processes.

Michael G. Danikas is Associate Professor with the Department of Electrical and Computer Engineering, Democritus University of Thrace (DUTh). He was with Eindhoven University of Technology, The Netherlands, and with ABB, Baden-Daettwil, Switzerland, before he joined DUTh. His research interests include breakdown in transformer oil, polymeric insulation breakdown processes, vacuum breakdown, partial discharge activity at inception voltages, simulation of electrical trees in polymeric materials and nanocomposites and partial discharges in rotating machine insulation

Masahiro Kozako is Assistant Professor at Kyushu Institute of Technology (KIT), Faculty of Engineering, Department of Electrical Engineering and Electronics, Japan. He was with Waseda University, Graduate School of Information, Production and Systems, Fukuoka, Japan, before he joined KIT. His research interests include partial discharges, gas insulated switchgear, and properties and characteristics of nanocomposites. 